\title{
Preliminary contemplation on Exchange Value
}

\author{
Harshad Dave
}

Additional General Manager (Retd.), Gujarat State Fertilizers and Chemicals Ltd. (GSFC), Vadodara,Gujarat, India.

\begin{abstract}
Exchange Value is a vital term of economics. Exchange Value is born by an exchange process and the exchange process is the life line of the human society. Exchange value gets influenced by various parameters. These parameters are discussed here. It is also tried to investigate on the linkages among human characteristics and economics through the process of exchange. The nature of influence of the parameters gets transformed into unethical ways and means as and when time and circumstances permit so. Today, a dense flow of exchange processes incessantly flows through our society and has become a life line for the existence of the society. Unfortunately the flow is polluted with unethical influence on the process of exchange and this subject matter is discussed in this article. Successful application of abilities in unethical ways and means to secure a favorable exchange ratio could be realized only with the help of government brasses and public servants and ruling politicians. The application of abilities on unethical ways during the process of exchange returns with an advantageous exchange ratio on either side party who is more unethical. The wealth/resources accumulated with unethical part of exchange process become a special influencing parameter (Capitalistic parameter) to undermine opposite party in future exchange. Ultimately, it turns into a race to hold maximum unethical resources to dictate most advantageous exchange ratio in all future exchange processes. This is one of the prime causes that drag our society into downfall to ugly peril.
\end{abstract}

Key words: exchange value, typical ability, preconditions, working group, WG, barbaric ability, civilized ability, trinity.

JEL Classification: A13, A14, B21, F43, F50, I24, O12, P16, P26, P48, Z13.

(C) The Authors, 2018. This article is published with open access at Sumy State University.

\section{Introduction}

If we go through the writings of prominent economist on various vital terms of economics like value and exchange value, we shall find difference of opinions, arguments and countering to them. Even today different theories are popular. However, I have tried to explain constitution of value in my article "The constitution of value, Part1". Here, I have separated out use value and value from forms of value. Exchange value is one of the most vital forms of value. There are so many economists in past and even in present who attempt to explain value through exchange value. Though exchange value is a vital term of economics, it is completely independent of value. Exchange value is born through a process of exchange between two commodities (many times money as one commodity on either side). I have tried to introduce the anatomy and physiology of exchange process that ultimately births an exchange value. I have tried to discuss on the linkages of human characteristics with economics in exchange process. It is also discussed how unethical acts enters the process of exchange and ultimately brings seduction and peril in our society. Readers might realize the floating nature of exchange value. The described constitution of the exchange value might give the idea of my saying that value cannot be comprehended through exchange value. In other words, one cannot explain constitution of value with the help of exchange value.

\section{Literature Review}

If we go through the views on exchange value right from Aristotle to Theory of value by Karl Marx and from Marx to latest Austrian theory of value based on utility, marginal utility and diminishing marginal utility, we shall learn that exchange value is not systematically analyzed as far as concerning to all the parameters that influence the exchange process. Sometimes it is treated as if exchange process is being carried out for pleasure, sometimes it is treated as a source of value. There is no consideration given to the influence of human characteristics on the exchange process and its linkages with economics. Many a times, many authors discuss exchange process as if it is an ideal process between two gentlemen but they did not consider practical happenings in our society while an exchange process takes place. Here it is tried to reveal all the parameters that 
exert influence on any exchange process in our society. It is tried to narrate a profile that constitute their foundation of ethical and unethical human characteristics along with the linkages with economics.

Fetus of exchange process. The presence of process of exchange in a human habitation is the first and foremost symptom of its being a human society. Otherwise, I believe, men were making their living in a group but it could not be designated as a human society. We never see deliberate and purposeful process of exchange in wild life system as it happens in human society.

The process of exchange is the greatest milestone in human history. A habitation, where people were making their living in a group of men/women and members with same blood (or others also), constituted a group living. Such group living, where no benefits of any inventions and discoveries were realized to some minimum level, was no more distinguishable from other examples that we find in a group living of wild dogs, hyenas, wolfs, mongoose etc. However, even when they could realize to enjoy some benefits of primitive and empirical discoveries and inventions, they were still in the group living only. It was not a human society. They also lived in a group with some untold, unwritten rules and followed instinctive group discipline. However, their group living cannot be compared to human society. There are innumerable differences between group living and human society. However, presence of process of exchange in a group living is the prime one and that makes it a human society.

Let us imagine a first event of a deliberate and purposeful exchange in a group of people living together sometimes somewhere on the Earth. It was the first step towards birth of human society. The first exchange was the first cry of a kid just came out of its mother's womb and later on evolved as human society as the events of the process of exchange increased there in. A primitive group of men with the repetition of events of exchanging there in the same group at one place on this planet earth might be accepted as first human society on the earth. Though we do not know where and when it came into existence.

The stress that I give to exchange process and it transforms a group living into a human society is founded on two facts,

a. No human society might survive if exchange process is ceased with any reason. Inevitably it will compel man to make his living within the framework of natural laws, if exchange process is eliminated totally.

b. It was and it is inevitable to keep the functioning of the society alive by...

Adopting system of 'Division of labour'.

$>$ Development and application of abilities (other than those warranted in wild life system) in men for making living.

$>$ Making inventions and discoveries and using them as supplements to the abilities.

Maintaining uninterrupted availability of subjects of the abilities.

$>$ Maintaining and following the preconditions by the occupants of the society and that is inevitable for the functioning of the social system. (-for preconditions you should read my article "Ability - The spine of economics")

The above task could be fulfilled and realized only if the exchange process is adopted by the society. It is next to impossible to comply above conditions without exchange process.

Process of exchange and division of labour are two flanks of one coin. The evolutionary development in the process of division of labour is homogeneously synchronized with process of exchange. Division of labour explored the possibility of making living for those who lacked the abilities warranted for maintaining survival in natural wild life system. Let us address the mass of people who do not have ability of making survival in wild life system and still they make their living in a habitation as a working group. They work in the habitation through the process of division of labor and make their living as a working group (WG). Maintenance and survival of the WG was dependent on the system of division of labor.

At the same time, the people in a WG did not have the qualified abilities for maintaining survival in the wild life system, or they were incompetent for the same. However, they were successful to develop some typical (different) abilities in them that were in demand to support the functioning of the production system evolved there with the help of discoveries and inventions realized at the time. This process of development of typical abilities that are applicable on natural resources to realize benefits of discoveries and inventions through productive system is the process of division of labour in the human habitation there. In other words, the realization 
of the benefits of inventions and discoveries applying them on various material resources of nature was possible only if various people are available with some different abilities that (typical abilities) were otherwise not recognized in wild life system by nature.

It is a fact that we always face pressure of surplus population in our society. This troubling pressure did prevail in ancient time also when men were living in a primitive group. The surplus population used to set to level when some of them were proved incompetent to exhibit required abilities on the events and occasions while making living in wild life system. Such people (the surplus population) had opportunity to survive if they work within habitation area only i. e. away from wild life system. Development in discoveries and inventions provided such opportunity. For example, a typical combination of labor power and intellectual power in the task of making a fishing-net develops an ability to prepare a fishing-net. The various abilities that are warranted to prepare a fishing-net are not recognized by wild life system as a means or source of survival.

However, men could develop such abilities in them. The system of group living provided an opportunity to them to survive through the application of such abilities that were, otherwise, not recognized by wild life system for making living. While applying the ability to manufacture fishing-net, it did not necessarily warrant the man working on fishing-net manufacturing activity to giving his exposer to wild life system. Those who were unable to face challenges of wild life system they were under the shadow of looming threat from all the wildlife challenges. But, the same were linked with the sentiments of their parents who were active members of the group/habitation making living. It was not possible to feed those who are unable to face challenges of the wild life for an indefinite length of time, but they were with a link of sentiments of their influential parents as told above. The parents found an opportunity to feed them from the enhanced productivity (increased quantity of fish catching using fish-net) in fishing yield and this arrangement became reliable system to satisfy sentiments of parents for those who were otherwise incompetent to survive in pure wild life system.

Moreover, it could be realized even remaining within the habitation (safe) area of the WG. Also, it reduced and relieved them from getting exposed to face challenges of wild life system directly. However, the developed abilities warranted for two inevitable resources for their application. One resource is supplements to the abilities and second one is subjects of abilities. This is discussed in my article "Ability - The spine of Economics." in my book "Elements of Economics". The fishing net might assure substantially higher yield in fish catching task. But, manufacturing of fishing-net requires various tools and skills. These tools and skills are supplements to abilities (tools, devices and accessories for knitting). Necessary raw material required for manufacturing the fishing net are the subjects of ability to make a fishing net (i. e. threads/fibers, material for floats and pull rope etc).

Now, summarizing the above views, it makes clear that the possibility of making living with different abilities* (*knitting a fishing net - not recognized by wild life system) might be realized provided,

\section{Appropriate system of division of labour functions.}

2. Supplements to the ability are made available to WG.

\section{Subjects of ability are made available without interruption.}

These preconditions are stringent and vital one. It is so stringent that breach in above conditions immediately creates a threat on the people surviving in WG. Even today, the division of labour is now projected as part of production system. If production system gets interrupted or raw material necessary for the production system is exhausted or necessary supplements for the application of abilities in WG are not available, total system will get collapsed and create a threat to the existence of people in WG. [WG- working group]

Above development contracted critical liabilities for the continuity of functioning of new system as an inevitable precondition of survival of people in the society. One of the prime liabilities was distribution of yield (production) of the productive work in the system. Up till now, man was not a manufacturer or producer of anything with purposeful intentions supporting his making living. He was accustomed to put efforts to acquire things/consumables produced either by nature or by others for his survival from surrounding world. If at all he produced anything, he was the consumer and was not conscious about surplus or left out, if any. It was sure; he was no more interested in the things that are not useful to him. Operating of process - Division of labor and application of labor (with typical abilities) of WG constituted the first primitive system where men worked and produced something that was to be consumed by or used by others. In other words, they produced deliberately for others. This became plausible on the basis of discoveries and inventions made by man. A part 
of population worked on material and produced for other people in the group. The others used them and produced something useful in such a quantity that was much higher than their requirement. The others were no one but another set of WG using fishing net to catch the fish. The higher yield in fish quantity supports the living of all the people of the group.

[NB: I think, it is only with human social system where systematic and deliberate productions of things are done with predefined goal and purpose. Otherwise, we do not find such joint task of production in wild life. However, I admit here, if I recall the movie "Papillion", I saw at one scene in the movie when the hero Steve McQueen was hiding himself in the dense jungle of Amazon after an escape from his imprisonment at French Guiana, South America. There in the jungle, it was shown an army of red ants. The army was cutting small pieces of green leaves of a plant and taking them inside a burrow in ground. I did not know how the pieces of the plant leaves were useful to the aunts at that time. After a long time, I came across the reason for the same from other source. I learned that the ants stake the pieces of leaves in a room inside the ground burrow. Atmospheric heat and moisture in weather encouraged a growth of typical fungus that gets developed on the surface of the leave pieces. The byproduct of this fungus is one type of sugar and that sugar is consumed by the aunts. If we consider above process/activity by the red ants as a deliberate and purposeful production of sugar, it is not wrong. However, the same family/group is a manufacturer and a consumer here. There is no exchange. But it cannot be compared with our production system that developed in leaps and bounds. There might be still more examples that might contradict my assumption that "The deliberate and purposeful production for the use of other people is exclusively in human society only", but they are in no way comparable.]

Let us go back to our discussion. The yield from division of labour might got distributed within the frame work of untold unwritten rules of the group. Various factors like muscle power, feelings and opinion of majority, potential or vitality of role in the prevailed system, age, blood relation, sex attraction and many other aspects were the parameters of influence to determine a quantity of the share in the yield. As far as quantity of yield remained adequate or higher than the required one for the satisfaction of the subject need of all, it (the distribution process) might remained smooth and streamlined.

All the days are not same. There might be an occasion when the total yield might fall shorter than that of required one. Under the circumstances, distribution became more critical. I believe, this distribution process and contemplation on the distributed quantity, ways and methods of the distribution pattern by obviating people there in the group created a first impel in the minds of some of them and that sense of impel was de-testing to them.

If there is a question in your mind that why they sustained with the unfair practice, then, I remind you that these people were no one but those who did not have competency to survive against the challenges of wild life system as they were lacking in the warranted abilities for the same.

Let us say that the set of all the abilities that secure making living in wild life system is a barbaric ability. We shall address the other abilities that are not recognized by wild life system for making living but the same are valid and recognized by the prevailing socio economic formation, as civilized ability. This is not a trifle notion. Even today also, when difference of opinion prevails and preconditions of social system are not honored (i.e. social system fails), there always surfaces out barbaric abilities to settle the differences.

Later on, when the events and observations got repeated in the distribution of the yield as discussed above, they sensed it with a known and familiar feeling of detest. We recognize today the same feelings as an unethical act. I believe such events of unpleasant feelings compelled them to streamline their own thoughts and feelings to ascertain "what distribution pattern, otherwise, should be?" and that introduced first sense of ethics. Ethics could be discovered by evaluating repeated unethical acts of some people and making analysis or contemplation on the same by the victims and other intellectual people.

[NB: We are not deviated from our subject matter of "Exchange value" but we are preparing a back ground for the subject discussion.]

I do agree, the event of grabbing a kill from a cheetah by a lioness immediately after the cheetah preyed it with hard effort is no less painful scene for us. When we see the lioness calmly eating the kill preyed by a female cheetah whose hungry kittens are waiting for their mother with something to eat on the Tv screen, a wave of sorrow and agony against unjust passes through our mind. But, it is the law of nature where inability of the cheetah to overpower the lioness muscle power paid for it. However, the event is in compliance to natural laws. 
Here, in our case, the group habitation has formed a system of working for some people (WG) with such abilities that are not recognized in wild life system by nature. Also, the people doing fishing in field might not have accrued the lucrative yield without the use of the accessories and facilities produced by WG. In other words, the same would not have been realized by them without the fishing net. This fact leads to the realization that the new system of working and making living by WG cannot be governed and administered exclusively by natural laws of wild life. This could be the first wave of departure of human society from wild life system.

Not only that, it (the departure) opened new roads towards such issues that man had never faced during his journey he made since he was an ape. The whirl of thoughts in their minds regarding process of distribution was not same for the distributors and that of receivers. The distributors were more inclined towards facts of natural laws to up held their cause to justify the distribution pattern they adopted. While receivers were rising their cause and justification on the vital role played by the efforts of WG to make supportive accessories available to the group that worked for fishing to secure a higher yield.

The invisible debate on this issue commenced right from the day when first human society came into existence to even till today, but, at some point of time, as man became more civilized, the debate surfaced out in dialogue and action also. The question- "When did we depart from wild life system and established (or evolved with) a human social system?"- might have an answer in the transition period which taught men that enjoyment (realization) of benefits of inventions and discoveries warranted for compliance of some such rules and precedents in the system of group living that might not be logically be fitting with natural laws of wild life system, rather against them also. This argument seems to me valid and logical one.

At the same time, the counter argument is also logical. It says that any distribution that is not based on and not in compliance with the rule of nature- "it should be proportionate to the potential of ability (barbaric) recognized by nature in wild life" - it is against the natural rule- "might is a right". It is the prominent law of nature and prevails since birth of first life. Above struggle of contradiction in two facts always remained in human society and emerged with different forms depending upon the prevailed socio economic formation of the society at the time. Whenever the social system failed to regulate and control the functioning of the society, the application of natural laws automatically and immediately became applicable on the members of the society as if they are under control and regulation of wild life system.

NB: While going through the above discussion, as told earlier, I do not depart from my subject matter i. e. exchange value. The subject matter of discussion on exchange value is a big task and it is necessary to prepare a platform on which the discussion on exchange value is to be carried out. Ethic is also one of the vital terms. Ethics is one of the influencing parameter to regulate exchange value.

Here above, we discussed only one example of a group of people working for fishing and a group producing fishing-net. As the society evolved with new discoveries and inventions, there were many groups WG1, WG2 ... WGn, working for collection of the jungle products, agricultural system, animal husbandry, poultry farming etc. Every group engaged and put efforts to acquire some particular good or consumable etc to satisfy either their own needs or that of others.

I think, it was the first lesson man was learning that a quantity of a commodity or substance that is beyond his capacity to consume might have a status other than a left out. Perhaps he was becoming aware of the sense and feelings of others for the left out that might satisfy their need/s. I believe, initially surpluses might be given without any obligations on either side. Unconsciously man might be aware of use value of substances (i.e. goods, consumables etc) in general. But he was not conscious about difference between use value and value of a substance (*please see my article- The constitution of value, Part 1).

The prevailed practice to give surplus without any return shows that the man of that ancient human habitation was at very primitive intellectual status. He was neither conscious about his pending unsatisfied needs at the event of giving surplus to others nor he had any advance vision for his forth coming needs likely to emerge in near future and if the surplus might be linked with it. Also, he might not find (detect) any other man with a different surplus material/thing to exchange with. This shows his primitive intellectual level.

Of course, there might be a group living. There might be occasions when a person P1 did not get his needed substance (or commodity) from other person $\mathrm{P} 2$ to whom he had frequently released surpluses with him (with P1) without reward. Here memory of the occasions of releasing surplus to P2 and memory of the occasions of regretting to release surplus to P1 by P2 might have come into conflicting thinking. The controversy in the above two sets of occasions might have generated deceitful impels. The impulses tempted P1 to ponder on it. 
Observation, contemplation, and happenings of practical events then after ultimately returned with a sense that introduced man (here P1) to be considerate on his future needs also. The sense of consideration of future needs empirically introduced his conscious to a typical use value in the surpluses on his hand. The sense of this typical use value was the fetus of exchange value. The man realized that the surplus commodity under his possession and on his hand has of course use values for his various future needs that might be linked with one or more characteristics of the surplus commodity, but it might also have one more typical use value that is known as exchange value.

The empirical and unconscious understanding about the typical use value became the foundation stone of first concept of exchange process. This exchange process gets regulated and controlled by more than one parameter of influence. I believe that parameters of influence on exchange process were very few (might be counted on fingers) in primitive human social habitation. As the human society developed with discoveries, inventions, intellectual development in philosophy, evolution of economics and other subjects, the various aspects of consideration in exchange process also became complex. There were many more parameters of influence to regulate an exchange process in human society of medieval period compare to that of in ancient casual human social habitations. The society developed in leaps and bounces after steam engine was invented. The shoot up in development of social systems, institutions and infrastructure with the help of science and technology have turned our social transactions so complex that now it is impossible to enlist all the influencing parameters in an exchange process today.

As discussed above, when various groups worked in the social system with some typical abilities (civilized ability), the efforts made with specific purpose get returned with a yield and we named it production. The production was generally in higher quantity due to the above set up depending upon the resourcefulness of natural wealth and other parameters. It is also a fact that man cannot make his living only on one commodity/good or consumable under his command. However, the same commodity might remain surplus with him (or with a team/group) after his need is satisfied. It might have taken hundreds or thousands of years by the men of the time to understand that the surplus on their hand is the promising source of managing other substances of their needs. The surplus under command with each man and presence of his unsatisfied need for other substance that is out of his command was one of the cause, and simultaneously, the bitter reminiscences of his experience after releasing his surplus in past to any one in a good faith (as discussed above) without claiming return, was the second cause that tempted him to adopt a process that sorted out both the problems in one go.

This process was an exchange process. As pointed out above, the process of exchange is a function of various parameters. I have already discussed partly on exchange process in the article "Views on Barter" and "The constitution of Value, Part 1" in my book "Elements of Economics" so I do not repeat that part here. However, it is necessary to discuss on influencing parameters moderately. It is not possible to detect all the influencing parameters in our present complex society; however, I have tried to enlist them to the best of my endeavor. The young scholars of economics might work on it and add more parameters that escaped from my working.

Before we go for analyzing the parameters that influence the exchange process in society, I shortly explain the types of exchange process that generally take place in our society. I have segregated them in four types.

1. Exchange between two commodities.

2. Exchange between commodity and service*.

3. Exchange between money and service*.

4. Exchange between two different services*.

*(service - intellectual as well as physical labour)

The list of influencing parameters for above all the types of exchanges might not be the same, however, for the sake of simplicity as well as to control the length of this article/paper, I shall discuss only one, i. e. the type 1 (Exchange between two commodities.).

The parameters that influence the exchange process. When two persons $P$ and $Q$ are intended to exchange commodities (cmdt1 and cmdt2 respectively) with them and if the process of exchange is realized with an exchange ratio acceptable to both the parties, it is most vital, debatable and interesting issue that requires fundamental investigation about the fact "How this ratio of exchange is ascertained and determined?" Here I have put my views on the same. 
[NB: While discussing the same we shall use the symbolic example of exchange between P and Q as well as cmdt1 and cmdt2 as above.]

There are various influencing parameters that exert vital influence on the process of exchange, and ultimately determine an exchange ratio. But, unfortunately, this point- consideration of influence of the parametersgenerally does not find enough stress during the vital discussion among scholars of economics regarding exchange value. I have attempted to discuss on those parameters to the extent possible here bellow,

\section{The list of the parameters:}

1. Quantum of labour and cost sustained (invested) on the commodities to get their possession.

2. Lack of adequate knowledge about commodity in exchange process

3. Potential of affinity (propensity) in either party to satisfy the subject need that is linked with the commodity in exchange.

4. Possibility to sustain without subject exchange.

5. Knowledge about alternate source of availability of the commodities in exchange process.

6. Ability to study present environment in the market concerned to the subject commodity and vision for future prediction.

7. An exchange for recovery purpose.

8. An exchange under acquaintance, relation and under-impression.

9. Process of exchange where more than one party negotiates on either side.

10. An exchange where either or both parties have poor recognition of the quality/specifications of the commodities in exchange.

11. An exchange under adverse or favorable circumstances and under helplessness.

12. An exchange carried out in artificial environment.

13. Lack of adequate information about market environment with either or both parties.

14. Influence of misleading propaganda and rumor having concern with the exchange process:

15. Exchange under threat and pressure.

16. Exchange with a purpose to oblige or for ethical consideration etc.

17. Exchange with a purpose to acknowledge an appreciation by either party.

18. Different hidden intentions to be upheld through the process of exchange.

19. Process of exchange carried out under instigation by others.

20. Process of exchange carried out just for showmanship or to impress someone.

21. "Capitalist Parameter".

[NB: We shall discuss first 20 parameters in our present discussion. The "Capitalist Parameter" at no. 21 will be introduced at appropriate time during our discussion.]

Let us discuss the above parameters point wise as well as shortly. However, I point out to the reader that each of the above parameter is discussed in a way that following aspects get incorporated in the discussion,

a. The short explanation about the profile of its (parameter's) influence.

b. How does the influence (effectiveness) of the parameter get linked with the abilities and characteristics of human being? How does it ultimately get linked with the economics?

c. The pollution in the exchange process - The cursed opportunities, social environment, dormant characteristics in man that instigate him during exchange process to expose and apply his unethical characteristics to control the process of exchange in a way that exchange ratio gets determined in his favor.

The integrated effect of such exchange processes, where exchange ratio is determined favorable to either side (party) by the summarized influence of effective parameters out of above mentioned list.... where the influence of one or more parameters is artificially and deliberately molded with the help of unethical characteristics of the man, ultimately creates a social stress and strain in the system and institutions of the society. The stress and strain become one of the root causes of some tough social issues like corruption, food adulteration, criminal offences, sexual abuse, human trafficking etc.

Quantum of labor and cost sustained on the commodities to get their possession for exchange. This parameter is the most vital as well as ethically justified parameter of consideration. It influences the process of determination of exchange value (exchange ratio) between two commodities in the exchange process. It 
has a vital role in the constitution of economics. If we scrutinize the situation, reasons and causes of application of labor-service analytically, it has most common purpose to develop (create) a commodity with some targeted characteristic/s from a raw material. We might nest our thinking as follow,

a. Creation of a commodity with required characteristics by working on one or more materials named raw material.

b. Getting possession of the commodity through last exchange process (generally we call it purchasing) between dealer and consumer.

If we analyze with microscopic vision we shall realize that,

i. There is an end user with his need. The end user has knowledge about one or more commodities that might satisfy the subject need.

ii. The end user is ready to exchange resources under his command against the subject commodity that has characteristic/s to satisfy the subject need/s.

iii. He might agree to exchange the resources under his command against the subject commodity at some exchange ratio acceptable/affordable to him.

iv. There are one or more raw materials that might be processed through one or more processes to produce the commodity for which the end user is prepared to exchange.

$\mathrm{v}$. There might be one or $\mathrm{n}$ numbers of processes carried out on different raw materials that were available in natural form without single human processing on them, and the commodity might be produced ready to exchange with the consumer against the resources with him after completion of above set of $n$ number processes.

vi. If we travel through the path between raw materials to finish products, we shall find application of labour and processes of exchanges on the path stage wise.

vii. Major and vital part of constitution of economics subject gets accommodated on this path. Also, "Application of labour" and "Processes of exchanges" both are the prime sources of constitution of economics.

If we contemplate on the above vision and study the happenings on the subject path between raw material and end product, we shall realize that there are two prime processes that constitute a vital and sensitive part of economics. The two prime processes are the application of labor and the process of exchange. For any commodity ready for exchange with end user, we shall find an integrated set of application of labor at various stages and a process of exchange between two stages.

The set of the application of labor is nothing but it is also a set of process of exchange where labor-service is exchanged with a reward to the worker. Many people make their living on such rewards only. It is true that exchange process between two commodities and that of between labor-service against a reward (money/wealth or other commodity) are not comparable. Both cannot be evaluated and analyze with the same parameters of influence. But it is the fact that any exchange process has a set of parameters of influence. The essence of saying is there will be a list of influencing parameters for exchange process between commodity 1 and commodity 2 . Also, there will be a list of influencing parameters for exchange process between labour and money/wealth or other commodity. But the few or more items (parameters) in above both the list might be different.

NB: Here we discuss about parameters of influence during process of exchange between two commodities only. The topic of exchange of labor-service against a reward is a very wide and deep subject. It also gets influenced by various parameters to determine an exchange ratio between labor-service and reward. So it cannot be discussed here. However consideration of its integrated influence should not mislead our present discussion.

Here, application of labor also influences each stage of the set of exchange process while determining an exchange ratio and that cannot be over looked. Not only that, as the progress in stages advances towards end product stage (finished product), every time, next sequential stage gets influenced by integrated effect of the previous stages. If I am not mistaken in my understanding, I agree with Karl Marx that there is nothing but addition of labor on every stage. Only I differ at one point and that is difference between value and exchange 
value. I firmly believe that every addition of labor influences its exchange value but in no case it influences its value. The concept that "it adds to the value of the commodity" will lead to many controversy and confusions. Every price or cost is not a value of the commodity. Price is the exchange value, and value has no link with exchange value. Every addition to cost will surely influence its exchange value but its value will remain same.

[Please read my article - The constitution of value, Part 1].

If we summarize above discussion, it is clear that determination of exchange ratio in any exchange process is a function of various influencing parameters.

If you agree with the above concept, you will agree that an exchange value (exchange ratio between two commodities) can never be expected uniform, even at same place and same time and for the same commodities, because potential of influence of each parameter varies case to case. It is a fact also. We find different exchange ratio between two commodities frequently. When it is a fact, it is absurd to determine a value of a commodity on the basis of its exchange value or to comprehend value through exchange value.

As said above, there is stage wise application of labour. Apparently there are two types of labors, one is physical labor and second one is intellectual labor. However, there can never be an application of a physical labor without traces of intellectual labor in it. So, it is impossible to separate out intellectual labor and physical labor. However, it is fair enough to consider physical labor as only physical labor work where traces of intellectual application are apparently very mild. As labor work also relies even on intellectual work invariably, it means, a same labor work done by different men with different intellectual ability will differ in overall efficiency as well as in final quality/quantity output. That is how the human characteristics get linked with the influence of this parameter (i. e. parameter 1 under discussion) and ultimately the influence plays a role to determine the exchange ratio and ultimately it links human abilities and characteristics with economics.

Now, let us see how unethical practices get encouraged during exchange process. The fact discussed above opens an opportunity for either party to treat the influence of the parameter in a way that the determination of the exchange ratio turns to his favor. Suppose, $\mathrm{P}$ and $\mathrm{Q}$ are the manufacturers of cmdt 1 and cmdt 2 from raw materials respectively. When consideration of various aspects are under way to determine an exchange ratio between cmdt1 and cmdt2, Q might have a judgment what best reward P might have paid to the workers on production of cmdt 1 and $\mathrm{Q}$ is likely to count on it. If $\mathrm{P}$ pays minimum possible reward to the people who worked on cmdt1, the difference between the judgment of $Q$ for the reward and that of actual paid by $P$ will surely determine a favorable part of exchange ratio. Both will try to pay lowest possible reward against processing of their commodities cmdt 1 and cmdt2. This tendency gives birth to various social abuses also. I think such a mind set (to give minimum possible reward to worker instead of reasonable*) is empirically evolved in the minds of men. The master works out tricks and treatments that will make him to pay his workers less. It will bring his labor cost far lower than that of likely considerations (estimation) of Q to work out the same.

As this difference goes wider, $\mathrm{P}$ gets more and more favorable exchange ratio. It is the same case vice verse for $\mathrm{Q}$ also. The race to bring labour cost lower ultimately leads to unethical means and tricks. Application of such tricks needs cooperation and support from social system and related institutions as well as backing from government brass and a systematic tie among manufacturers and ruling crook in the society. Ultimately it warrants an unethical net-work in the society to support the above task. It is impossible to realize the subject task without people with low (dirty) morale working in the social system at different level and with diverse powers to act. As it is not possible without the positive help of ruling team, it again introduces various social pollutions like corruption, breach of laws, criminals and their protective system (so called religious places to hide them), availability of hired offenders, heinous people working for their (offenders) protection (socially reputed advocates and solicitors) etc. But, this did not emerge within a short time. It is the evolved capitalistic system and it has to happen with change in socio economic formation with industrial development. Remedy to this problem is not easy task but at least we should be bold enough to educate our new generation about the facts that are happening in our society and root causes as discussed above.

Lack of adequate knowledge about commodities in exchange process. Suppose there is a person in market to purchase timber to manufacture a table for his use. If he is not able to recognize various types of timbers of different trees, he might purchase Sapele (Entandophragma cylindricum) wood on the name of Rosewood (Dalbergia spp.) or Teak (Tectona grandis) and might pay exchange value based on the later one. But, he receives the former one only. If he had through knowledge and experience to detect and locate all the genuine 
differences among them, he would have never agreed to the exchange value he paid for Sapele wood under wrong impression.

If either party realizes that opposite party does not have required expertise and experience, the party might set exchange ratio in its favor taking advantage of lack of knowledge of opposite party. Here, this parameter compels man to stand in market either with all required knowledge or with a hired representative with above knowledge and experience. If he fails to take every care as above, his resources will get exhausted against high exchange ratio for a commodity under fake belief (presumption) that it corresponds to his required characteristics and standard. It also reveals the fact that absence of ability makes you to bear with higher exchange value and it results into faster exhaustion of earned resources with you. Your capacity to satisfy balance needs in your priority list vanishes due to exhausted or shortage of necessary resources. This is nothing but an impelpush to you towards poverty. When such multiple pushes gets together in anyone's life, he slowly gets a shift towards poverty and slum area. Here also, the competency and ability to recognize various types of timber is ability or characteristic of a man and it is linked with economics as shown above. Before we discuss further, I would like to point out one important fact.

I would like to discuss one fact here. We all are aware that there are innumerable commodities available in market of present society. Various people are in market to get any one or more of them from the market. Here it is an exchange between consumer and seller. It is for money on one side and commodity on other side. It is not possible that a man in present society must acquire perfect knowledge of each and every thing/commodity for which he is in market. If he does not have the knowledge, there are fair chances that seller might take advantage to make the exchange ratio favorable to him (seller). Reader will agree that it is now impossible to each and every person to be expert of all the commodities that he might required to satisfy his various needs. Here, it is the felt necessity of the time that social system must play a role through its constitutional structure that one will hesitate/fear to take advantage of lack of knowledge of the client. The invisible demand that no seller is expected to take advantage of weakness (helplessness) of the knowledge of client is a precondition of the social constitution while it evolved. But, unfortunately such preconditions are systematically violated to make exchange ratio unethically favorable by the sellers/manufacturers. Such systematic violation in the preconditions is plausible only if support of trinity ${ }^{*}$ is secured. Here again, they (sellers/manufacturers) need immoral people in the social system everywhere. (*trinity - producers/sellers, public office holders and politician on ruling platform).

There are innumerable such preconditions in our social constitution. The anticipated working of social system remains healthy, only if the above all the preconditions are fulfilled by the people of the society. Here is the game played by sellers, public office holders and politician on ruling platform. Institutions with big name like Consumer's Protection Board, Vigilance on Quality Control, Weight and Measure Regulation Office etc. There is judiciary (legal) as well as police force for remedial actions, if any departure is detected. I have explained how the above public offices and their executives become a farce including legal system and police force in the article written by me. I have discussed reasons for the departure from the above compliance in my article... "Where the shoe pinches?", so I do not repeat them here. Let us come back to our discussion.

If one's inability pushes him towards his destruction, it is a natural course. Then, there is a logical question "Where does the wrong lie?" Here, the point of objection is that; in fact, above rule is absolutely valid for wild life system where partiality and favoring has no place. Here, on one side, the evolution of human society is founded on the policy and principles that application of laws, rules and regulation must prevail uniformly, impartially and without prejudice for all. But, a systematic, invisible and untold/unwritten coordination among wealthy people, ruling team and corrupted public servants provides an environment where end user (consumer) systematically get looted of his valuable resources during exchange process that unethically remains advantageous to the manufacturer or dealer or seller.

Further to this, either party enjoys advantageous ratio of exchange against the commodity under his command. If the opposite party was expert enough to recognize the quality and departure in it, the opposite party would have agreed with lower exchange ratio only.

I believe.... "The part of the exchange ratio that is born out of unethical influence of the parameter in any exchange process, the same part becomes the source of the wealth and profit." Here ultimately that looted part is nothing but the unpaid labour (as truly said by Karl Marx), but it is equally vital to know how it is getting drained out from the resources of the holder. Here, it is also to be noted how human weaknesses and various characteristics get linked with economics. 
Moreover, above parameter tempts some of the unethical and dormant characteristics in men (here between $\mathrm{P}$ and Q) to take unethical advantage of lack of knowledge of opposite party. It is also a fact that some manufacturer starts business of duplicate and it is the result of influence of this parameter that unethically assures advantageous exchange ratio. We come across many cases where either party receives a commodity that differs with that of his anticipated one. Sometime it might be the case of cheating or sometime it is tactful misleading. But, here a scholar of economics might visualize how ethics is born and linked with humanity as well as economics. Not only that, the derived exchange value (exchange ratio) between two parties with above cheating misleads observations and conclusions of economists. It causes controversies in exchange ratio for the same commodities where the influence of subject parameter is nil. Let me put two live examples here.

Today, $4^{\text {th }}$ November, 2017, when I write this article, I confirm that there is repeated warning that we receive in Whatsapp by well wisher to be aware of dummy rice. It tells that China exports fake rice corns manufactured from some synthetic material. Now some people (agents) in India import the same. Ultimately it reaches to various places where the same are mixed up with natural rice and lastly reaches to consumers, hotels and restaurants etc. Whoever the end user purchases it, he believes it is natural rice only, but in reality he gets synthetic rice. The exchange ratio that he accepts is for natural rice only, but, out of his knowledge he receives fake synthetic rice in his dish after cooking. Should we not consider this ugly parameter of influence while we discuss vital topics of economics and concern of exchange value? One more example I cite here.

There are very reputed and prestigious ice-cream manufacturing companies manufacture ice-cream from vegetable ghee (processed vegetable butter) in India, sometimes not even vegetable butter but from mutton tallow. On the basis of popular knowledge of recipe and definition of ice-cream one will surely presume that icecream manufactured by such companies must be from cattle milk only and naturally it is supposed to be from the milk only. The world known milk product producer "Amul" introduced a petition on this issue, because Amul was manufacturing ice-cream from milk only.

Hon. Court issued an order to all the companies who were manufacturing the ice-cream from vegetable butter to print clear indication/note on the product packing clarifying to consumer that the ice-cream is not manufactured from milk. But, before the day of court order, since years together, people consumed those products under fake belief that the ice-cream they purchase and consume is manufactured from milk only. Purchase of ice-cream was an exchange, where consumer was under good and logical belief that he is being served icecream that has been manufactured from milk. Dealers/suppliers/manufacturers were aware of this fact and they were claiming the exchange ratio as if it is manufactured from milk. Here are the two examples as above, but one might find innumerable examples where exchange ratio is turned into favor by supplying duplicate material.

Here also, politicians, and responsible social institutions helps in the above game as a part of the conspiracy with a share in the loot through corruption. Such conspiracies are surely linked with human unethical characteristics, and process of exchange is linked with economics, now we might visualize how economics is linked with human characteristics.

Potential of affinity (propensity) in either party to satisfy the subject need. This is one of the most vital and sensitive parameter that exerts grass root influence not only on exchange process to determine exchange ratio among/between the commodities but the economic subject itself has a major bearing on this parameter. There is a vital link between human characteristics and economics established by this parameter.

You will agree that no man is equal in this world by his nature and characteristics. His all the choices are influenced by his nature, heritage and characteristics developed in him and by other aspects also. When a person is a party in a process of exchange to determine exchange ratio, his propensity for the commodity under the command of opposite party plays a vital role in exchange process. If the nature of the need is not critical one, in spite of it, if the propensity of the party is high enough to get possession of the commodity, it will offer an opportunity to opposite party to exploit the situation.

There are innumerable needs that are not critical. There is no threat to our health or life if any one or more is not satisfied. However, there are many people whose propensities ride on their wisdom. Such people are with very weak will power to sustain without the subject commodity that he might get in exchange with his valuable resources. The received commodity has, of course, competency to satisfy the need to whom he has given prime priority. Whether the emergence of satisfying the subject need is critical or not is doubtful and debatable. However, the person $(\mathrm{Q})$ is convinced to satisfy the same with a prime priority to it and it surely creates 
an intense propensity in $\mathrm{Q}$ to satisfy it. But the need is not of critical nature. When opposite party $\mathrm{P}$ rightly realizes about the high potential of the propensity of the party $Q$ for getting command over cmdt1, the party $\mathrm{P}$ will surely dictate an exchange ratio favorable to it (to party $\mathrm{P}$ ). As the potential of propensity of $\mathrm{Q}$ grows more, the exchange ratio remains more and more favorable to the party P. Here also, the subject weakness is one of the characteristics of any man. The weakness of having excess propensity has an influence in the determination of an exchange ratio. This also shows how our characteristics cast their role in constituting the economics.

If $\mathrm{Q}$ is with high will power to sustain without the satisfaction of subject need and his preparedness to drop out the exchange process against offered exchange ratio by $\mathrm{P}$ might compel $\mathrm{P}$ to reduce it to the extent possible. However, we find people in our society without such strong will power. Under the circumstances, they get exploited with an unfavorable exchange ratio.

Here it is a very tricky point of discussion. One might argue, when excess propensity is the characteristic of a man and he is willing to sacrifice his valuable resources to satisfy his subject need with exchange ratio unfavorable to him, it is his concern when the resources earned by him are lawful. Prima face it seems logical but it is equally harmful to the health of the society.

Let us discuss it shortly. If $\mathrm{P}$ is with high propensity for a cmdt2 with Q and Q is aware of it. Q offers an exchange ratio to $\mathrm{P}$ and ratio is apparently unfavorable to $\mathrm{P}$. As $\mathrm{P}$ is helpless against his propensity for cmdt2, he agrees to exchange. It means Q should get a part quantity of cmdt1 excess based on the subject weakness in P. Our point is that the additional (partly) transaction of cmdt 1 due to propensity of $\mathrm{P}$ for $\mathrm{cmdt} 2$ is justified one or not, its consequential effect on social constitution are also to be worked out. Here, I put some of the points and request that economic scholars as well as sociologist should think on them.

Do we agree that it is justified one and one should take advantage of this and that of other weaknesses of men while they are in market with their resources? We are aware and we all should agree with a fact that, generally, the people are with so many weaknesses as well as helplessness. Is it affordable to give free hand to exploit them on every opportunity? If we study the history of mankind and steps of social development between the lines, we shall learn that few people are always prepared to exploit each and every opportunity to enjoy favorable exchange ratio as above. These people least bother about the fact that constitution of human society sustains harm by their action. The empirical knowledge of ruling team makes the team aware of the fact that excess harm to social constitution will lead to a collapse of working and functioning of social systems as well as institutions. If it happens, the vested interests of ruling team will be under threat. It is the reason the ruling team curbs and controls the above process of exploitation by enforcing some rules, laws and regulating controls.

Further to this, above control emerge with various opportunities for corruption to liberalize the judiciary as well as executive institutions permitting the above exploitation to the possible extent. The just requirement is that it should not reach to a level that threats the total social collapse. Ultimately the parameter becomes the cause of social seduction, bribing and corruption. Here also, reader can grasp how human characteristics are linked with processes of economics.

Possibility to sustain without the subject exchange. It is one of the typical abilities in man where he has to sustain without satisfying the subject need in the event when the negotiation in exchange process turns out abortive. Taking a decision not to agree with the unjustified exchange ratio and to face and bear with the consequential situation is also an exhibition of various abilities. In other words, an intellectual sight or vision that creates his best judgment on the nature and vitality of the need that ultimately constitutes a competency. It is a characteristic that get linked with the exchange process causing influence on determination of exchange ratio. He should have best judgment of self stamina to bear with and tolerate with the resultant consequences if the exchange process remains abortive but not to surrender unjustified exchange ratio. It calls for various abilities in a man. It tests his enduring capacity, his vision with matured thinking, his overall preparedness to sustain with minimum damage in the event if the exchange does not get materialized. It tests his ability to control the resultant damage and there are many other abilities having a concern.

Above discussed capabilities and competencies are deeply rooted and linked with human characteristics. Taking an example, $\mathrm{P}$ is aware of the fact that $\mathrm{Q}$ has a determination to manage without the cmdt 1 if exchange process turns abortive. Also, $\mathrm{Q}$ is prepared to face all the consequences that might emerge in the event if the subject exchange does not get materialized. If $\mathrm{Q}$ does not agreed with the exchange ratio offered by $\mathrm{P}, \mathrm{P}$ will 
have to give possible all the considerations to make the exchange ratio more favorable to $\mathrm{Q}$, provided $\mathrm{P}$ is comparatively more reluctant to face abortive exchange process. This parameter of influence is also linked with human characteristics as well as it exerts influence on exchange process also. Our vision for both the points will realize us how economics is linked with human characteristics.

Here we have discussed only a simple example but you might observe with analytical vision where above fact has become a social culture in market almost for all the items. Particularly, if you stand in a bazaar where tourists are most common visitors and sellers are hawkers, mongers and retailers with a cabin or tent. Here, generally, tourists are note in bad need of anything to purchase. We frequently find a scene that a tourist selects some item that he like to purchase, he asks to spell the price and hawker offers or communicates it. The tourist puts it back and slowly starts to move ahead in bazaar. Here it is the test of stamina if hawker is ready to afford to let go a client or the purchaser (here tourist) is ready to sustain without purchase of the subject item. To whom we say a method of bargaining. There are innumerable examples one might visualize if he analytically looks at the exchange process going on in market.

Here also, people have discovered all the possibilities to apply unethical means and tricks to create mock impression on the mind of either party as if one cannot sustain without the subject commodity as if the cmdt1 is an exclusive messiah to satisfy the respective need of $\mathrm{Q}$ and in the event, if $\mathrm{Q}$ fails to materialize the exchange, $\mathrm{Q}$ will be at great loss. We see such all the attempts by various strategy and actions of a marketing department of various products to impress upon the parties in the market for satisfying a need with whom its product is linked with. There are weak minded people in our society and they make decision on basis of the canvassing/advertisements and propaganda that have impressed them as if they cannot sustain without the cmdt1.

However, there are smart and wise people also who have all the abilities to evaluate and consider over all aspects of their subject need as well as consequential effects if the same is not satisfied, in the event, the exchange is not carried out. Enchanting advertisements and exaggerated claims for the fruitfulness of the product has become culture of the marketing department only on this base. Sometimes it adopts unethical ways and means also. Here they need help of the social rulers as well as public servants at various levels to over look on the false claims about benefits of product, paying silence on the hazardous characteristics of the product, keeping deliberate silence on tactfully misleading words and sentences in the advertisement and introductory pamphlets/broachers.

Here also, it is apparent that various characteristics of man get linked with the process of economics.

Knowledge about substitute commodity and about its source of availability in exchange process. If $P$ is aware of a fact that alternate commodities (cmdt 3 and $\mathrm{cmdt} 4$ ) are available for exchange from other sources, this knowledge will surely exert influence on the determination of exchange ratio. $\mathrm{P}$ knows that cmdt 3 and cmdt4 are also competent to satisfy his (of P) concerned need (might be with some different level of satisfaction) in the event cmdt 2 with $\mathrm{Q}$ could not be acquired by exchange. $\mathrm{P}$ will have upper hand while negotiating exchange process to determine exchange ratio with $\mathrm{Q}$. Reverse to this, if $\mathrm{P}$ is not either aware of the sources for availability of cmdt3 and cmdt4 and/or does not have knowledge that cmdt3 and cmdt4 are additional options, and $\mathrm{Q}$ is aware of this fact, $\mathrm{Q}$ will surely dictate for an exchange ratio favorable to him (Q).

Here also, the knowledge of above referred alternate sources, vision for the same, putting efforts to explore such sources etc have a deep concern to the person's (here P) various abilities, competencies and characteristics. This is the way economics get linked with human characteristics also.

Further to this, the parameter also leads to unethical activities to enjoy favorable exchange ratio. If Q manages that cmdt 3 and cmdt4 should not get any place in the near approachable market for any client as both are a potential alternative to cmdt2 with $\mathrm{Q}, \mathrm{P}$ has no go but to accept exchange ratio favorable to $\mathrm{Q}$. It happens practically in our society. Some influential people use all the unethical ways and means to retard or destroy all the alternatives to their product (cmdt2). Ruling politicians and public office bearers are mixed with them behind the curtain to support the task against corruption.

Let me site one example. There are various types of mangoes available in India and each type is a typical product of the respective area. There is interstate business for the mangoes. "Badami" is one type of mango generally get cultivated in the Karnataka state. "Keshar" is another type of mango and it is cultivated at Gir (Junagadh dist.) area in Gujarat state. As far as test and satisfaction is concerned "Keshar" is preferable, however, "Badami" is no less competent. Once upon a time, there was full availability of "Badami" mango in 
Gujarat state under interstate business. People were fully enjoying "Badami" mangoes as an alternate to "Keshar". This situation was not permitting "Keshar" seller's lobby to enjoy price rise in "Keshar". A lobby of "Kesher" dealers exerted a situation to stop or hinder this alternate of "Badami" to "Keshar". Here, political heads (in ruling) and high level public office bearers all blessed and mixed up to resist entry of "Badami" into Gujarat state with all unethical means. As the clients (people of Gujarat) did not get the healthy alternative, there was no go but to afford higher price of "Keshar". There are innumerable examples one might get if he analytically examines the tricks and scams played among these trinity (marketing scoundrels, heinous politicians, and hopeless public office agents).

It is absurd to blame and fight anyone out of the above trinity (or all the three) as they are the locust developed on erroneous social constitution of human society. As it is not our subject of present discussion I do not write any further on it, but the parameter presently in discussion is one of the prime sources of social seduction and links with human characteristics.

Vision for future prediction. A man who has an ability to synchronize his past experience, present knowledge and his intellectual ability classically, he will have always better judgment on the likely happenings in near future and there are fair enough chances that the predictions might turn out true, if not guaranteed. When $\mathrm{P}$ has future vision casting the prediction and $\mathrm{Q}$ is lacking in his ability of prediction/vision, under the circumstances, there are fair chances that process of determination of exchange ratio will yield advantage to $P$.

No doubt, this influencing parameter is also linked with human abilities and characteristics as seen above. Here also, the parties in exchange process have fair chances to play with unethical actions. Many times, either party play a trick in which tricks of misleading propaganda and floating rumors are used. The propaganda and rumors certainly confuses the opposite party and there are fair chances the victimized party might take a wrong decision under the influence of propaganda. The process of exchange ultimately returns with an exchange ratio beneficial to the party that plaid a technique of making propaganda as well as floated rumors/misinformation. However, if the opposite party is also competent to judge and evaluate the real status remaining immune from the influence of propaganda and rumor, the determination of exchange ratio will also remain out of influence of the same. Here it is to be noted how unethical movement sprouts or gets induced in the process of exchange where an attempt might be made with the help of propaganda and rumor to secure a more favorable exchange ratio. Also, we might work out how the human characteristics are linked with this vital economic process of exchange.

An exchange for recovery purpose. This is also a parameter that exerts influence of exchange process innocently if not polluted by heinous people. Sometimes it happens that $\mathrm{P}$ is in market to exchange cmdt 1 that is useless or a burden to him with any reasons. Under the circumstances he is mentally prepared to accept whatever available exchange ratio he gets. In spite of it, $\mathrm{P}$ will try to get maximum possible favorable ratio but his intention is more towards getting rid of the cmdt 1 rather than investing or involving more resources to secure a good exchange ratio. However, if he does not get it favorable he might accept much lower ratio also, because he is intended to get rid of comdt1. Generally he (P) will try to conceal the fact that he is in exchange process for cmdt 1 just for recovery purpose. In the event, if $\mathrm{Q}$ is not aware of the fact, $\mathrm{P}$ might win an exchange ratio at marginal or more difference with generally prevailed during the exchange between cmdt 1 and cmdt 2 . Otherwise, $\mathrm{Q}$ might get the exchange ratio much favorable to him (Q).

Generally such exchanges are offered on the basis of "As it is where it is". However, heinous people in market artificially sells regular product that is drown out from his production unit on the name of damaged, scrapped or spoiled part of main production to escape from taxes and other charges. I recall, there were some markets (Dhalgarwad and Manek Chawk bazaar in Ahmedabad city, India) over flooded with such products that were brought out from production unit under different causes to escape from taxes. There where shirt pieces on sale but all were brought to the market from the mills just under heading of damaged scrap pieces of clothes under above scam only. Such scrap pieces were auctioned (fabricated artificial auction on paper) on weight basis to some agents. The same pieces were then after reached to above market and sold out. Here I point out to the reader that how exchange process and its influencing parameters are closely knitted with each other and how they become ethical support to the social system and its functioning. At the same time, how each parameter is spoiled with unethical ways and means under the blessings of the trinity.

Exchange under acquaintance, relation and under-impression. Sometimes $\mathrm{P}$ and $\mathrm{Q}$ are acquainted to each other with some social relations and past obligations. When they enter into an exchange process for cmdt 1 and cmdt2, the agreed upon exchange ratio might differ from that of generally it remains in ordinary (normal) 
circumstances. We may find a different exchange ratio between cmdt 1 and cmdt 2 with a large difference with reference to an average exchange ratio that generally prevails between the same commodities. Here, the above parameter causes an influence on the exchange process.

However, this parameter is not that innocent as it appears to be. There are fare chances, if an impartial investigation is carried out on any exchange process where exchange ratio is abnormally different than that of in normal exchanges of the same commodities, one will surely find a corrupted favoring. There might be very few cases where this subject parameter might have exerted its innocent and ethical influence only. Otherwise, in most of the cases the influence of this parameter is highly manipulated only. There are innumerable scams one might find where exchange (sale) is done with abnormal ratio and justification is on the ground of this parameter with manipulated ethical values.

As far as under-impression is concerned, I have observed many people who make their purchases for a particular brand of whom they are under impression. When you go under impression your competency to evaluate any subject matter with various aspects, pros and cones will vanish to all most nil. I think, it is one type of psychological weakness in some people. Unfortunately, the people in our society with such weakness are not scant, but there are plenty. Marketing departments of manufacturers of all most all the products are trained to exploit above weakness in the people as soon as their brand becomes a popular one. The producers/sellers increase the price just on brand name and this increase in multiple folds compare to that of a same product with competent specifications but produced by less popular producers. Here also, one might see how people's characteristics and economics are linked.

Process of exchange where more than one party negotiates on either side. If $P$ is aware of the fact that there are various parties other than $Q$ with cmdt2. All are ready to enter exchange process for the cmdt 1 with $\mathrm{P}$. P will have upper hand to influence the exchange process for getting favorable exchange ratio. This is simple and logical where each party with cmdt 2 will count on various parameters as above and will try to offer a ratio of exchange attractive to $\mathrm{P}$. Here also, it is on the overall ability and expertise of $\mathrm{P}$ to detect and recognize the fact on which the opposite party has offered such an attractive (favorable) exchange ratio. You will agree that some of the parameters out of the above list of twenty parameters are such that the benefit accrued from the attractive ratio cannot compensate the loss contracted due to unfavorable compromise/departure in some of the parameters in the list.

For example, a bail of cotton available with different exchange ratio from different suppliers needs verification of quality of cotton as well as moisture contained in it etc. When there is more than one party in exchange process on either side, careful verification of some of the parameters and a comparison among them become critical for the other (opposite) party. This process also becomes a test of abilities and characteristics of men in exchange process. This is how economics is linked with human characteristics.

Further to this, Q might learn that strength of $\mathrm{P}$ to bear with the time, in the event the process of subject exchange fails, lies in an alternate supplier of the same commodity. It is human nature $\mathrm{Q}$ will surely think how to diminish his (of P) alternate supplier. This will artificially make P helpless to accept the exchange ratio offered by and advantageous to Q. I am trying to surface out the fact that reveals how unethical thoughts sprouts in the minds of the party in exchange process and ultimately it becomes a social seducing. The ardent lust to enjoy a maximum possible favorable exchange ratio ultimately leads man (here $Q$ ) to diminish alternate supplier even with unethical ways and means.

If we prepare a model or a theory on marketing process as if all the participants in the market transactions/dealing are holy, saint and honest people wedded to ethical values, the theory/model and our conclusions and predictions will always be misleading. It practically happens that competitors are destroyed with various means and methods. Why it is so? It is because just to dictate most advantageous exchange ratio to opposite party where he will not find any alternate suppliers. This task of destroying competitors is a big task in advance socio economic formation and complex net work of present society founded on industrial productive system, here also the trinity play vital role. They introduce system of license and permit, they enact laws and rules in a way that government system might interfere and stop anyone at any time and on any ground. Judiciary system and other government institutions also act as puppy and poppet in waiting to render the above service. Perhaps it is a misleading task to draw a theory on free market when practical happenings in the markets are diametrically contradictory and opposite. I believe, it is sin to teach our new and fresh generation on the basis of fancy free market. 
Exchange where either or both parties have poor quality recognition of the substance in exchange. When a person is in market to manage a commodity to satisfy his one or more needs, he should be fully aware of the specifications and characteristics that the commodity should have, to satisfy the subject need. Otherwise, he is likely to pay an exchange value for such a commodity in which the essential characteristics are either absent or of inferior quality. There are innumerable cases in our society where people exchanges with such goods where anticipated satisfaction do not realize as the goods do not have genuine specifications making them competent to satisfy his subject need. I think, birth of "consumer's protection act" and "warranty guaranty clause" seems to be the legitimate child of this parameter of influence. Why this act might came into force some times in the history of human society has a reason.

It is inevitable to run (function) all the systems and institutions in the society with their smooth (trouble free) performance. If their functioning is held up or paralyzed beyond limit due to any reason, social system itself will collapse and this collapse will result into population destruction as well as it will disrupt the vested interests of many wealthy and influential people. No ruling team risk total collapse of the system. The people, whose vested interests are likely to get engendered due to the above collapse, will support the ruling team for control and regulation of social affairs to avoid total collapse.

On other side, it is impossible for all the men in the society to be expert and master of the specifications of all the commodities/goods that a man generally needs to consume in our present advance society. At the same time, all the men are part of WG (working group) belonging to any of the social systems and institutions. If these systems and institutions do not function, collapse of total society is imminent. When the events of cheating in the goods specification taking advantage of people's lack of knowledge and their helplessness became a frequent problem, ruling team of the time feared total collapse of the society if the practice to cheating in quality is not curbed. This gave birth to the concerned laws/acts as above. The trinity cooperates with the dealers and manufacturers to curb the performance of the above said acts/laws at bare minimum level.

Generally we all are aware that when we go to market to purchase provisions and households, we come across varieties of product and different manufacturers. Let us take one item... say umbrella. Now we find varieties of colorful umbrellas with artistic design and intricate facilities. The very purpose of umbrella is to get protection from rain and sun light. Other vital specification that we reasonably expect from the umbrella is its trouble free service and long life. This is the prime and basic characteristics/service we expect from an umbrella. Its attractive look, its colorful dome cloth and artistic design of its various parts are the subsidiary points of consideration. It is the task of manufacturer/seller to shift our attention from verifying if the presence of prime characteristics that makes the umbrella durable, efficient to satisfy the basic purpose, easy to operate and sturdy to sustain with its handling impact etc, are present or not.

If the attention is not diverted and a client finds opportunity to verify the level of above basic qualities, the entire manufacturers will have to compete among themselves on above quality characteristics and it is a costly task. It is mandatory for them to find out some weak characteristics in the clients to shift the above attention. If a man is not able to detect the vital and critical aspects out of various aspects for any subject matter under his dealing, it is a serious weakness of him. Here also, the manufacturer/seller takes advantage of the subject weakness and introduces various trifle characteristics in the umbrella. When client approaches to purchase an umbrella, he unnecessarily gets bogged into the trifle characteristics as discussed above to make his choice. If you carefully analyze above attention shifting, you will also learn that manufacturers/sellers have now shifted their competition from costly affairs of maintaining quality of basic/prime characteristics of the umbrella to a competition through trifle characteristics. This safeguards the favorable exchange ratio of manufacturer/seller during the exchange process between client and seller. Here also, you will realize how our various abilities and characteristics are linked with economics.

Exchange under adverse or favorable circumstances and under helplessness. When a milkman is in market to exchange a quantity of milk with any other substance that might satisfy his one or more needs, empirically it is understood that he has to finalize his deal within a span of a limited time as milk is perishable and cannot endure for a long time. When the opposite party making deal with the milkman is aware of this fact and the substance (commodity) in deal against the milk is not a perishable one, milkman always remains under pressure to fulfill the deal in time. This situation surely gives impact on the determination of exchange value of milk. Generally, farmers of orchard/vegetables, meat seller (butcher), fish catchers etc has to remain alert to avoid victimization of perishable characteristic of the commodity on hand when its preservation facility is 
not available. When either party in the exchange process is helpless or passing through some typical circumstances, and opposite party has knowledge of it, the determined exchange value in such exchange process might be different one for the same commodities on other occasions.

Today, when I write this, it is $21^{\text {st }}$ Feb 2016. Since long we hear about migrating refugees from Syria to Europe. The people who migrated and reached to other society as refugee might be with some valuables taken with them when they left their native/home land. Naturally these people need to exchange the valuables with them for the first hand prime provisions necessary for initial survival. Here the migrated people are circumstantially in helpless situation on new land/hosting society. The parameter of "circumstances and helplessness" will have dominating influence on the determination of exchange value of those valuables. If it is ethical,justified and lawful or not is a different philosophy, I just talk about the fact and actual happenings during exchanges under such circumstances. Other parameters do have influence on the exchange process, but, here "circumstances and helplessness" parameter plays vital role in the determination of exchange ratio during exchange process.

If we sharply analyze the market of exchange between two commodity, we find plenty examples where either party is deliberately and purposefully trapped into artificially created helpless circumstances just to induce the party to agree at lowest possible exchange ratio for the commodity in his hand and favorable to opposite party. When a farmer reaches to market with his agriculture produce, this is the popular unethical technique played by the marketing people that purchase the same from the farmers. They make unity and create an artificial environment as if the produce brought to the market by the farmer is an over flooding commodity with lowest exchange value. The financial and social circumstances of the farmer create helplessness and compel the farmer to agree at lowest exchange ratio for his agriculture produce. The trinity plays a vital role in this looting in support of market agents/dealers or manufacturers where the subject agricultural product is a raw material. It shows how ethical values and human characteristics are linked with economics.

Exchange carried out in artificial environment. Various tricks are plaid by the parties in the exchange deal where one of the trick is to create such an environment that should confuse or mislead either party in a way to impress that materializing of the deal will be in its favor otherwise it might contract a loss, if the deal is not carried out immediately. This dilemma of mind naturally tempts the party to make a deal in haste or to soften his bargaining power for the favorable exchange value that he had predetermined in his anticipation. Let us take one example where such technique is used in a deal of very big turnkey contract. The party that is going to issue for a turnkey contract talks with more than one vendor of the same concern/field. The master (client) party opens negotiating talk and other techno commercial discussion with one of the vendor who is not a likely choice for final deal. However, a mock deal of negotiation to allocating a turnkey contract creates an environment that creates pressure on other vendors to remain reasonable during negotiation with them. Such negotiations, creating environment of preplanned pressure technique, watching and observing the approach of other vendors in competition, evaluation of the situation, judgment and predictions etc are the prime characteristics that influence the above negotiation in an exchange process. Here also, it is apparent how our various characteristics get linked with economics. I do not write anything how this parameter might get polluted with unethical ways and means as it is self explanatory.

Lack of adequate information with either or both parties. If person $Q$ decides to make a deal to exchange (purchase) a commodity or a good with P. Here, Q is the person who has contracted a supply of the same good (purchased from $\mathrm{P}$ ) to other third party R within scheduled time limit. Q goes to $\mathrm{P}$ for the same good to get it in an exchange (purchase) deal to forfeit the supply to $\mathrm{R}$ in time. With any reason, $\mathrm{Q}$ is near to time limit date of supply to R. If the information about the contracted time limit is reached to P, P becomes aware of the fact that $\mathrm{Q}$ is helpless to meet the delivery schedule in time without materializing the exchange between them ( $\mathrm{P}$ and Q). Here, the exchange process will surely be influenced by this information and the determined exchange value will be favorable to $\mathrm{P}$. If $\mathrm{Q}$ manages successfully to hide the subject information from $\mathrm{P}, \mathrm{Q}$ will be at an advantage due to lack of some information to $\mathrm{P}$. That is why; even today, when a deal/contract is under the consideration for materialization, parties in the deal strive for all the detail situation and circumstances the opposite party is passing through.

Now, taking advantage of such information and compelling opposite party (here Q) to agree upon an exchange ratio in favor of $\mathrm{P}$ to the extent possible is a fact and to what extent the enhanced exchange ratio under the above situation influences economics and which type of errors and irregularities it might introduce in the social system and institutions are matters of research. If taking advantage of such information and exploiting 
it as above is ethical, then the application and interpretation of ethics in religion and judiciary system must be redefined. A good social system can never sustain with different interpretations of ethics in any two compartments of society, but, unfortunately our present society is evolved with above practice and that ultimately leads to criminalization and corruption in the society.

There is no need to mention, how the trinity takes advantage of this parameter totally unethically. Private contractors always smuggled the information of internal situation of the public department. The brass of public offices leaks the sensitive information secretly and partially to a particular party about the work tender and its adjoining all the details against corruption amount/favor in any way. Political crook provides all type of services to help the above task between public office and the contractor. Political crook also makes necessary arrangement to safeguard the contractor, in the event, if any outside other party/person raises a voice against this and contractor makes him silent with any unlawful means and ways. Ruling members of the political party renders their earnest services with all possible misuse of his office power to pass on verbal instruction/cautions, if people in the public office show non-cooperation in the above task, practically demolishes to any one systematically if he does not obey and this policy crops up highly corrupted and morale less people in government systems and institutions.

This parameter is one of the vital parameters that have capacity to influence the exchange process unimaginable potential of influence on exchange. Investigate any big deal by public (government) office for purchase and construction; you will immediately get the above fact.

Influence of misleading propaganda and rumor on exchange process. Spreading propaganda or rumor that concerns to either party in the deal of exchange by opposite party surely proves to be an effective parameter of influence on exchange process. When farmers put their efforts to get agricultural produce, there are various types of rumors or propaganda used to make an easy deal with those farmers who got victimized of propaganda or rumor. I site few of them here.

1. "There is a biological disorder spreading and likely to destroy total corps and effective pesticides are going to remain in short supply due to labour unrest at manufacturer's works."

2. "There is a record breaking high production of corn and everywhere market is going to become over flooded."

3. "Weather forecast confirms that there will be a heavy rain out of season within few days."

Such propaganda and rumor leads the farmer to be in hurry to escape from the heavy loss. Any exchange carried out with feared mind set will surely going to put opposite party at an advantageous status.

Rumor and propaganda are one of the most influencing parameters to influence the exchange ratio unethically.

Exchange under threat and pressure. Generally we are accustomed to erect our theory and conclusions after a study of cases and happenings in the subject matter on which we are working. But, it is a poor practice if one takes ethical and ideal cases to work on. I think such practice will lead us to conclusions that might immediately get trapped into controversy. I firmly believe, we should always take all the cases of happenings and facts irrespective of their merits as well as their ethical/non-ethical or lawful/unlawful status. When happenings of such practices are frequent and in routine, one should not avoid them keeping out of consideration. I believe such practices exert a vital influence on the subject matter, and avoiding their consideration will surely keep us away from the reality.

Today, there are innumerable exchanges take place every day in our society. There are many exchanges that are materialized under threat and/or pressure on either party. If the party was not under threat/pressure, the exchange ratio would have been different one. It would be more favorable to the party if it was out of threat/pressure otherwise. If we examine and analyze the cases of exchanges when farmers reaches to marketing yard where they sale their market produce, a systematic unity is formed among the purchasers of the agriculture products. However, there are purchasers who are ready to purchase the products at higher exchange ratio but they are suppressed by the influential big heads of the marketing yard. If they over look their untold and unwritten threat and purchase the products at higher exchange ratio, they will be under threat from any direction and ultimately such marketing person might have to either surrender the big heads or created situation throws him out of the business. Here risk of life might not be eliminated. 
On other side, if the farmers are not under pressure due to some parameters like perishable character of the product or financial crisis at home, farmers might think to store the products, instead of selling it at lower exchange ratio or they might go for direct sale to end consumers in retail. But such options are on paper only. If they go for the same remedy they will be harassed from multiple directions by the agents of social system and institutions. The trinity also either work against them or they (brass of systems and institutions) will remain as silent spectators when hired criminals are demolishing them. Ultimately, without going into detail scrutiny, it impresses us that farmers are democratically at liberty to sale their products in a free environment of free market and they get an exchange ratio that is emerged under free exchange process. But, a sharp analysis and scrutiny of the fabricated free market will convince any wise man that the total process of exchange is under invisible compulsion, full of threat and systematically created pressure. I am talking about this threat and pressure. Here also, the trinity plays its role with classical coordination among them.

This capitalistic system is the evolved system that came into existence along with social evolution of whole human society. The exchange process is an inevitable life line for the existence of present society. Whether it is right or wrong, ethical or unethical, justified or unjustified that is not within the purview of this discussion. But, it is a fact and it has a concern to many social as well as economic issues. If these facts are avoided while discussing the vital topics of economics and our discussions, opinions and thoughts are erected just on presumption that very holy and innocent saints are in exchange process with high and ideal ethical qualities and as if they are wedded to best human values, the outcome and conclusions worked out from such discussions/thoughts will be farcical only.

Exchange with a purpose to oblige or on feelings of ethical consideration. Sometimes, either party in exchange process (to determine exchange ratio) is intended to oblige the opposite party with any reason. An exchange ratio determined under the above circumstances might not be in logical compliance to the ratio generally prevails in the market in normal and ordinary course of exchange process between the same commodities. Sometimes authorities and representatives of either party in exchange process are with a mind set to make a charity or sometime the determination of exchange ratio is more influenced by the obligatory consideration/s of either party. Such exchange ratios are not logically in line with those that got determined under influence of other parameters.

However, there are fabricated exchanges on above base. If a contractor wants to bribe a big brass holding public office or a political head on the chair of power, naturally it needs to be done in a way that they can retain their honest impression in public image. This task is to be carried out by the contractor/supplier safely to escape from its publicity. There are hundred thousand ways to do this. Many times close relatives of such people who are in market or business at other place are used as a media to realize the task safely (or difficult to link). His close relatives are obliged with an exchange generally carried out in their working with exceptionally low exchange ratio or their goods are purchased with exceptionally high rate under the direction of the contractor. If one examines such exchange individually he finds abnormal exchange ratio, but if he verifies/seeks the reason of the abnormal exchange ratio, it is fabricated with some mock ethical or obligatory reasons behind it. But, if a fundamental investigation is made the fact will reveal the unethical (corruption) part.

However, there might be some true cases also where the abnormal exchange ratio is truly with a reason where either party's consideration is purely ethical or to oblige the opposite party with some ethical reasons.

Exchange with a purpose to acknowledge an appreciation by either party. It is self explanatory that any exchange if carried out between two parties where either party agrees with a ratio of exchange under the consideration of acknowledgement of appreciation to opposite party, the ratio of exchange might not be in logical compliance.

I do not write any more on this parameter as it is just in line with the above parameter 16 . However, it is not immune from the influence of human characteristics as well as its unethical applications.

Different hidden intentions to be upheld through the process of exchange. There are many cases of exchange where this parameter is prime one compare to consideration of other parameters. Many times either party enters into exchange process where prime cause of exchanging is with hidden intention/purpose like...,

To cause pressure on third party.

$>$ To impress upon others.

> To restrict other's performance/business. 
To create artificial shortage of the subject commodity.

And many other reasons might be involved directly or indirectly. However, the exchange ratio derived with a prime consideration of this parameter might be different than that of in the case of consideration of other parameters with equal or more weight. This parameter is one of the parameters that cause unethical influence on exchange ratio. It is easy to understand by any experienced reader how and in which way the points a to $d$ are used to create unethical and artificial situation in a dealing/exchange process to enjoy a favorable exchange ratio.

Process of exchange carried out under instigation by others. An exchange carried out between P and Q where $\mathrm{Q}$ has been tactfully instigated to get cmdt 1 from $\mathrm{P}$ by any means or ways. Here, the determined and agreed ratio of exchange might be different as the influencing parameter of instigation has prime influence in the process of determination of exchange ratio compare to the other considerations of other parameter. If we analytically view such exchanges, we will realize that human weakness also plays part on either side. Sometimes we confess on such exchange that an exchange carried out under deliberate instigation of either party, would not have materialized if the instigated party was intelligent, wise and experienced one. But, unfortunately, the party was weak in the above ability and was missing competent characteristics and that was exploited by the opposite party to instigate it to enter into the subject exchange.

Process of exchange carried out just for showmanship. Every man wants to get distinguished or impress other. It is a most common weakness in man. Though it is a weakness in the minds of all men at different level/potential, it is an unavoidable fact also. Sometimes, a person enters the exchange process to impress upon other (or to impress some targeted party/person). An exchange ratio that is determined under the influence of this parameter might differ than it would be in other cases. Here also, the characteristic of a showmanship or intention to impress upon others is considered as one of the weaknesses in the man. A man, entering an exchange process just to impress upon others and agrees to an exchange ratio, surely links his characteristic with exchange process and ultimately with economics.

\section{A closing discussion through some thoughts. Thought 1- Potential of influence of active parameters:}

I point out to the reader that there are innumerable exchange-processes that are carried out daily in our present society. The influence of above discussed parameters might vary case to case and might get deviated from place to place and also on time line depending upon situation and circumstances. Not only that, it is not mandatory that each and every parameters must exert influence in every exchange process. Out of above all parameters, some of the parameters are most likely and common to exert influence. Let us address these parameters as active parameters. Here the influence of other parameters might not be present. Also, it is uncertain to determine which parameter has exerted highest influence and which one stands with lowest influence without fundamental and case to case investigation after the exchange gets materialized. Each active parameter in the subject case of exchange might have different potential of influence. Realization of a completed exchange process might be considered under integrated influence of all the active parameters in the subject exchange process. That is why each exchange process might be a unique one.

Thought 2 - A short discussion on ethics:

$>$ The subject matter of discussion on ethics is very wide and deep but here our discussion will be limited to economic point of view and concerning to our point of discussion on the exchange process in economics. I request readers to take note of the following points while they go through this article as far as ethical and unethical acts are used in the discussion.

$>$ A pure wild life in nature is the prime system and let us say it the zero socio economic formation.

$>$ As human society developed with the help of discoveries and inventions, we may stage wise segregate the various socio economic formations from the history of mankind.

$>$ Ethics does prevail in wild life also but comprehension about ethics there in wild life is different than that of today. The parameters of evaluation to determine, if an act is ethical or unethical varies as per the status of the prevailed socio economic formation.

Thought 3 - Segregation of integrated influence of active parameters into ethical part and unethical part:

If we look on our present society and its functioning, the society is flooding with innumerable activities at every day and on every minute. If the activities are scrutinized, one will learn that exchange processes have 
occupied a major share in them. While discussing on the above parameters that exert influence on the exchange process, it is clear that the overall (integrated or summarized) influence of above all the parameters, ultimately, determines the exchange ratio in the subject exchange process. I should point out to the reader that the potential of influence of each parameter varies with case to case depending upon time, place, situation, circumstances and many other known/unknown causes and forces. Each parameter has a close link with human characteristics (this is already discussed above). It is a fact that no two men are equal in their characteristics. Also, slots of abilities and potential of propensity to satisfy the subject need linked with the exchange process there in each slots during each exchange process varies person to person. It is not the presumption but it is the fact that is what I believe and I appeal to the reader to ponder (contemplate) on this and you will realize the same. Based on the above facts, it is absurd to expect that there should be uniform exchange ratio between two commodities in the society on every occasion.

However, it is also a fact that our society is functioning and performing on a production system as well as its distribution system. These systems cannot perform without minimum required manpower. Also, reader should keep in mind that the manpower is a set of working men where each one is working with his ability, competency and under the influence of his own characteristics as well as weaknesses in them. They work and perform at different work points within this frame work. The process of allocation/distribution of above working gets materialized through the evolved process of division of labour (please read my article of "Division of Labour") and this process of work distribution is not immune from unethical practices by men (this is discussed in the article "Division of Labour").

Now, if any one goes through the above facts, one will get convinced for the causes of the floating nature of exchange value. Wherever exchange value is stabilized between two commodities, it might be incidental or a result of deliberate control by ruling team of the society just to protect vested interests of some influential people as already discussed above and if such control is not carried out it might paralyze the production system and other functioning of various systems of the society risking the above vested interests.

Further to this, there are all the possibilities, as discussed above, that the influence of each parameter might be separated in two slots. One is natural and ethical slot and second is unethical slot. It means the summarized/integrated influence of all the active parameters have two parts. One part is ethical part of influence and second part is unethical part of influence.

[NB: Before going further in the present discussion, I clarify that it is a debatable issue to determine if any act is ethical or unethical. There might be hundred thousand opinions about an action in favor of and against it while evaluating it if the same is ethical or unethical. However, I believe, if we take an act as ethical one while randomly selected majority people in the society opine in favor of its being ethical.]

Now, if an exchange takes place between $P$ and $Q$ for commodity cmdt 1 and cmdt 2 respectively and the return received against the exchange process by $\mathrm{P}$ and $\mathrm{Q}$ both might be divided into two parts. One part of the received return is ethical part and second part is unethical part as the case may be and this might be true for both the commodities cmdt 1 as well as cmdt 2 received by $\mathrm{Q}$ and $\mathrm{P}$ respectively on realization of the exchange.

It means, quantity of cmdt 2 received by $\mathrm{P}$ and that of cmdt 1 by $\mathrm{Q}$, each of them might be splitted into two parts (ethical part and unethical part), because victimization of unethical influence of the influencing parameters is not one sided. It is absurd to believe either of them is a saint. However, there are fare chances that the size of the each part (ethical or unethical) might differ for $\mathrm{P}$ and $\mathrm{Q}$.

Let us talk about unethical part of cmdt 2 received by $\mathrm{P}$. The total quantity of cmdt 2 that is possessed by $\mathrm{P}$ might be splitted in two parts. Let us say quantity (qnty $1_{\mathrm{p}}$ ) is an ethical part and qnty $2_{\mathrm{p}}$ is an unethical part, and qnty $1_{p}$ plus qunty $2_{p}$ comprises the total quantity of the commodity cmdt 2 with $P$. If we evaluate the share of qnty $1_{p}$ with qnty $2_{p}$ compare to total quantity of cmdt 2 with $P$, (let us presume) qnty $2_{p}$ is substantially higher. Because the overall integrated influence of parameters during the exchange process is largely founded on unethical ground.

$\mathrm{P}$ goes to market with cmdt2 (total quantity) for another exchange (fresh exchange) with R who holds a different commodity (cmdt3). Again all the parameters become applicable to the process of exchange between $\mathrm{P}$ and $\mathrm{R}$. The total quantity of cmdt 3 with $\mathrm{R}$ has also two parts qnty $1_{\mathrm{r}}$ (ethical) and qnty $2_{\mathrm{r}}$ (unethical) in line with discussion as above for $\mathrm{P}$ and $\mathrm{Q}$. 
Now, analyze carefully. All the above discussed parameters are applicable to the exchange process between $\mathrm{P}$ and $\mathrm{R}$ and one more parameter exerts its influence and that is "Capitalist Parameter" shown at sr. no. 21 in the above list. This parameter is.... "Influence of the unethical quantity of the commodities in exchange process possessed by the parties in exchange." Here, P and R both are commanding an unethical quantity of commodities (here cmdt 2 for $\mathrm{P}-\mathrm{qnty} 2_{\mathrm{p}}$ and that of cmdt 3 for $\mathrm{R}-\mathrm{qnty} 2_{\mathrm{r}}$ ).

Let us presume that $R$ has very small quantity (qnty $2_{r}$ ) of cmdt3 and qnty $1_{r}$ is a major part in total quantity of cmdt3. It means overall and integrated influence of first 20 parameters largely founded on ethical ground in the previous exchanges of $\mathrm{R}$ for getting possession of cmdt3.

Here $\mathrm{R}$ is in exchange process with $\mathrm{P}$ for $\mathrm{cmdt} 2$ and cmdt 3 respectively. $\mathrm{R}$ commands a major quantity of cmdt3 possessed on ethical ground. P commands major quantity of cmdt 2 possessed on unethical ground. The command on major unethical quantity of a commodity gives the party to undermine the opposite party in various ways and means. A person who hold a commodity in exchange process with an ethical major part of his commodity has to sustain a loss in exchange process as he cannot exert sufficient influence of all the parameters on ethical way to compete with unethical ways and means that are already exercised by the opposite party with the support of unethical quantity of commodity possessed by him. Not only that, a random third party who has also major quantity of cmdt 2 received/acquired on ethical ground and in need to have cmdt3 cannot compete with $\mathrm{P}$ as $\mathrm{P}$ has unethical quantity of cmdt2 in large.

This is discussed for one exchange process. But our society performs with exchange processes since beginning of the society. As exploration in science and technology progressed with millions of inventions and discoveries, the resultant industrial development evolved our social structure with innumerable exchanges in the society. If we go through the above facts of exchange process, we shall learn that every exchange process has exploitive approach towards the commodity that one has acquired ethically and for this task one must have unethical commodity on hand to give realization to the subject exploitation.

Capitalistic society is an evolved structure. Man's instinct taught him, rather evolved his mind set in a way that screwed him to apply his all the abilities in the process of exchange in such a way that he secures maximum possible advantageous exchange ratio in the deal. When he realized to lose the ground by ethical ways and means for creating influence of one or more parameters out of above discussed, he found out unethical ways and means for the same to secure his advantage.

The person who was generous and possessed good ethical quality got defeated in the struggle of determination of exchange ratio in the process of exchange. The unethical influence of one or more parameters deprived him of lawful ethical possession of his commodity at a disadvantageous exchange ratio. If it was a negotiation/struggle between two to determine an exchange ratio purely on ethical ground only, in the event, the resultant exchange ratio would have been different where there would have no sense of "advantage" but there would be a prime consideration of satisfaction of need/s linked with the commodities received by the parties in the exchange.

If we analytically view the warranted ways and means that are applied by a party to create unethical potential in the influencing parameters, we will realize that it is not possible for a person single handedly to create such influence. But such strategy warrants coordination among those who have good-will for evil acts. They automatically get conspired instinctively under evolution process of the society and to whom we recognize them as bourgeois. There is no point to hate bourgeois because they are the product of prevailing social environment as we see locust in some season.

There is always a competition among bourgeois themselves in the exchange processes. This competition is not for determining exchange ratio between two commodities but it is for securing major share in the total magnitude of exchange among various commodities in the society. This competition among bourgeois reveals their two images. They are most loyal and trust worthy allies when they have to cooperate to exert unethical influence in the above parameters, but they are most dangerous rivals when they are in conflict to secure major share in the total exchange volume in the society.

But one activity is common in both the struggle and it is to introduce unethical ways and means in the social system to win the struggle. However, they are aware that prevailing social system must function to safeguard their interest and over dose of application of unethical ways and means might risk a total collapse. The ruling team that makes its survival on the invisible support of the bourgeois has to regulate and control the practice of using unethical ways and means so tactfully in a way that social system should not get totally collapsed but 
the same system should facilitate the bourgeois to realize their interests to the extent possible. It is farcical situation, the member of the ruling team has to win as a representative of people and as soon as they are elected, they have to work as a representative of the bourgeois.

If we contemplate on the above structure of the exchange process, we shall realize that the situation automatically propagates an environment where there is an invisible competition among people to find out more and more unethical ways and means to create maximum hold on unethical wealth and this unethical wealth itself helps while competing other rivals in the field. I believe that this is the process that has played a vast role to make our social system corrupted and criminalization and many other social issues.

\section{Conclusion}

It is tried to reveal the operational constitution of exchange process, linkages of human characteristics with economics through the exchange process and its resultant effect on our society. Let us conclude our above discussion point wise.

$>$ Exchange process is the life line of our society. However, it is regulated and influenced by various parameters. Potential of influence of each parameter might be different in each case and it depends on the circumstances and situation, time and place... case to case.

$>$ The exchange ratio gets determined under the integrated influence of the above parameters. However, it is not necessary that all the parameters are active in each case.

$>$ It is the natural tendency of the parties in exchange process to secure favorable exchange ratio in every exchange process. This lust of favorable exchange ratio leads the parties to commission all the applicable abilities with them for the cause.

$>$ The human characteristics get linked with economics through the exchange process.

$>$ The struggle to determine favorable exchange ratio ultimately results into applications of unethical ways and means to make it in favor.

$>$ As the application of unethical ways and means warrants for support and cooperation in the subject task to bring unethical influence on the above subject parameters, it slowly evolves with a net work among likeminded low moral people in ruling team (politicians), brasses in government/public offices and manufacturing/dealer/wealthy people in exchange process and this trinity make a net work of seductive activities to secure the subject devils' cooperation.

$>$ With above anatomy and physiology of exchange process, people of the society have to rely on them (exchange processes) as exchange processes are a life line of present society. It is absurd to expect uniform exchange value between two commodities in a society for every exchange process.

$>$ Ultimately, every exchange process returns with a receipt of commodity (or money/wealth) in the exchange process where received quantity incorporates an unethical part on either or both the side.

$>$ The subject unethical part helps to determine (or secure) favorable exchange ratio in future exchanges.

$>$ The game of holding largest unethical part to undermine opposite party in future exchanges dragged people into a race and that ultimately played a vital role to contaminate our social constitution with innumerable breach of preconditions.

$>$ Exchange process is inevitable and life line for the survival of human society, the same exchange process has become a production plant of unethical values and unfortunately people does not have even clear knowledge of this fact.

\section{References}

1. Adam Smith.mWealth of Nation, Chapter IV. Of the Origin and Use of Money, Chapter V, Of The Real and Nominal Price of Commodities, or Of Their Price in labour, and Their Price in Money, 31-44.

2. Alla Sheptun. Philosophy of Money. Retrieved from: https://www.bu.edu/wcp/ Papers/Econ/EconShep.htm

3. Carl Menger. (2007). Principles of Economics. Ludwig von Mises Institute, Auburn, Alabama, Forwarded by Peter G. Klein. Reprinted. Chapter-VIII Theory of Money, 257-280.

4. David Ricardo. The Works and Correspondence of David Recardo. Edited by Piero Sraffa with collaboration of M H Dobb, Volume I. On the Principle of Political Economy and Taxation, Chapter XXVII. On 
Currency and Bank, 352-372.

5. Goettmann, Alphonse. Dialogue on the Path Of Initiation. Translated by Theodore And Rebecca Nottingham, Electronically Published By Nottingham Publishing. Translated from the original French:

6. Henry George, Robert Schalkenbach. (1935). Progress and Poverty. Foundation.

7. Henry George. The science of Political Economy abridged by Lindy Davies. Part-V Money: the Medium of Exchange and Measure of Value. Retrieved from: http://www.politicaleconomy. org/speV 1.htm

8. Herbert Spencer's. (1876-85), Principles of Sociology

9. John Lubbock's. (1870), Origin Of Civilization.

10. John Stuart Mill. Principles of Political Economy (1848).

11. Kenneth E. (2004). Boulding, General systems theory. The skeleton of science. E:CO Special Double, 6 (1-2), 127-139.

12. Mackellar, J. (2013). Participant observation at events: theory, practice and potential. International Journal of Event and Festival Management, 1-18.

13. Malinowski's Argonauts of the Western Pacific (1922).

14. Man Karlfried Durkheim. (1988). Hara the Vital Centre of Man, 1-109. Retrieved from: https://terebess.hu/zen/ mesterek/Hara.pdf

15. Marx (1959). Economic \& Philosophic Manuscripts of 1844, Progress Publishers, Moscow.

16. Menger, C. (2007). Principles of Economics. Ludwig von Mises Institute, Auburn, Ala, USA. Retrieved from: http://austrian-library.s3-website-us-east-1.amazonaws.com/books/ Carl\%20Menger/Principles\%20of $\% 20$ Economics.html

17. Neil J. Smelser, Richard Swedberg "The Handbook Of Economic Sociology". By Editors.

18. Weber, Max. Economy and Society. Retrieved from: https://archive.org/stream/ MaxWeberEconomyAndSociety/MaxWeberEconomyAndSociety_djvu.txt

19. Whitaker, J. (2001). Henry George, John Stuart Mill and Adam Smith. The American Journal of Economics and Sociology. p. 11 